Accepted for publication in Research in Developmental Disabilities

Title Page

\title{
Attitude and Key Word Signing Usage in Support Staff
}

Ellen Rombouts ${ }^{\mathrm{a}}$, Bea Maes ${ }^{\mathrm{b}}$, Inge Zink ${ }^{\mathrm{a}, \mathrm{c}}$

Corresponding and first author:

Email address: Ellen.Rombouts@kuleuven.be

${ }^{a}$ KU Leuven, Faculty of Medicine

Department of Neurosciences, Research Group Experimental Oto-Rhino-Laryngology (ORL)

Herestraat 49 box 721, BE-3000 Leuven, Belgium

${ }^{\mathrm{b}}$ KU Leuven, Faculty of Psychology and Educational Sciences

Parenting and Special Education Research Group

L. Vanderkelenstraat 32 box 3765, BE-3000 Leuven, Belgium

${ }^{c}$ University Hospitals Leuven, Campus St.-Rafaël

Department of ENT, Head \& Neck Surgery, MUCLA

Herestraat 49, BE-3000 Leuven, Belgium 


\begin{abstract}

\section{Background}

Support staff may diverge in their use of augmentative and alternative communication (AAC) and key word signing (KWS). AAC use is determined by multiple personal and environmental factors. In this study, the relation between KWS attitudes and usage was examined in support staff.
\end{abstract}

\title{
Method
}

Twelve adults with an intellectual disability who use KWS were each filmed during a dyadic interaction with two professionals from their service: one had received first-hand (1HT) and the other second-hand KWS training (2HT). Each communication partner participated with only one client. The professionals' sign usage was coded, and their attitude towards KWS was measured using a survey and single-category Implicit Association Test (IAT).

\section{Results}

1HT produced more signed utterances and distinct signs than $2 \mathrm{HT}$, and this increase had a positive, linear relation to IAT scores. Explicit attitude did not correlate with KWS usage, but did significantly correlate with the discrepancy between intention and KWS usage.

\section{Conclusion}

The train-the-trainer system may not reach its full potential as 2HT knew fewer distinct signs and consequently produced fewer signed utterances than 1HT. In contrast to implicit attitude, no relation was found between explicit attitude and KWS usage. Though the survey may provide valuable information, it may not fully capture the complex influences that shape AAC usage.

\section{What this paper adds}

In various qualitative studies, researchers found that individuals' attitude towards AAC may impede or facilitate AAC implementation. In the field of AAC, this relation has not yet been empirically studied. Also, AAC researchers have primarily focused on aided strategies despite that research has indicated that key word signing (KWS) may be used frequently in services for individuals with an intellectual disability. To answer to these research needs, the relation between KWS attitudes and usage was examined in support staff by combining explicit and implicit attitude measurements with conversation analysis. The present results were in line with findings from explorative studies. Furthermore, results suggested that evaluation of AAC implementation in a clinical setting requires a more in-depth approach than conducting a survey. 


\section{Introduction}

Without communication support, individuals who experience communication difficulties can become dependent on others. Augmentative and alternative communication (AAC) strategies may support communication and consequently enhance these individuals' self-determination and quality of life (Hamm \& Mirenda, 2006). Individuals who use these strategies employ their body (unaided AAC) or external means (aided AAC) to enhance or replace speech. This study concerns key word signing (KWS), an unaided AAC strategy that involves simultaneously signing key words during speech.

AAC use involves multiple stakeholders: clients (individuals with a disability), family, friends, and support staff (Beukelman \& Mirenda, 2013; Schlosser, 1999). The AAC skills, knowledge, and attitudes of each stakeholder can affect AAC implementation. Clients and support staff who use AAC reported that staff attitudes can facilitate or impede AAC use (Calculator, 1999; Johnson, Inglebret, Jones, \& Ray, 2006; Lund \& Light, 2007b). The relation between AAC attitudes or beliefs and AAC use is not straightforward as it is shaped by a complex interrelation of various personal and environmental factors (Calculator, 1999; Johnson et al., 2006; Rombouts, Maes, \& Zink, 2015; Smith \& Connolly, 2008; Trembath, Iacono, Lyon, West, \& Johnson, 2014).

Researchers studying the relation between environmental factors and AAC implementation have traditionally utilised qualitative research methods (Calculator, 1999; Johnson et al., 2006; Lund \& Light, 2007b; McCall, Markova, Murphy, Moodie, \& Collins, 1997; Murphy, Markova, Collins, \& Moodie, 1996; Smith \& Connolly, 2008; Torrison, Jung, Baker, Beliveau, \& Cook, 2007; Trembath et al., 2014). Presently, this relation has not been empirically studied. Therefore, we examined the connection between attitude and KWS use in staff by combining attitude measurements with conversation analysis. Because AAC researchers have primarily focused on aided AAC and a research study indicated that KWS 
may be used extensively in services for adult clients (Meuris, Maes, \& Zink, 2014), we examined KWS application.

\subsection{AAC Usage in Support Staff}

Support staff may find it challenging to use AAC consistently (Chadwick \& Jolliffe, 2009; Johnson et al., 2006; Rombouts et al., 2015; Trembath et al., 2014). The extent to which they use AAC can vary considerably (Meuris, Maes, \& Zink, 2015; Trembath et al., 2014); for example, Meuris et al. (2015) observed that trained staff produced 0 to 38 signed utterances during a 5-minute staff-client conversation. These authors suggested that this large range is indicative of diverging views on KWS.

A number of researchers have found that staff skills and beliefs can affect their AAC use. Staff are more inclined to consistently apply a communication strategy if they have received sufficient training (Calculator, 1999; Johnson et al., 2006; Lund \& Light, 2007b), if they believe the strategy facilitates communication (Johnson et al., 2006; Stans, Dalemans, de Witte, \& Beurskens, 2013), or if they understand its impact on a particular client (Bradshaw \& Goldbart, 2013; Graves, 2007; Purcell, McConkey, \& Morris, 2000). In contrast, staff who reluctantly use AAC may think: (a) that it is embarrassing (Meuris et al., 2015), (b) that the strategy is not adapted to the clients' needs (Johnson et al., 2006; Meuris et al., 2015; Trembath et al., 2014), (c) that it may have negative consequences such as stigmatisation (Lund \& Light, 2007b), (d) that their colleagues do not support AAC, or (e) that they do not have sufficient time or AAC skills (Murphy et al., 1996; Torrison et al., 2007).

\subsection{Relation between Attitude and Behaviour}

The attitude-behaviour relation has been studied extensively in social psychology. Fishbein and Ajzen (1975) developed the theory of reasoned action, a seminal behavioural model that maps the progression from beliefs to actions. According to its most recent adaptation, the reasoned action approach, correlations between individuals' background, 
attitudes, social norms, and (perceived) behavioural control shape intention and behaviour (Fishbein \& Ajzen, 2010). All these factors can influence AAC use, which renders the relation between certain beliefs and AAC use complex. For example, staff who believe in the benefits of AAC may nevertheless find it difficult to consistently use the strategy (Rombouts et al., 2015). In an interview study, the reasoned action approach was found to be a useful framework for explicating AAC use in support staff (Rombouts et al., 2015). Consequently, the reasoned action approach and its related models may be a sound starting point for measuring attitudes towards AAC.

An indirect offspring of Fishbein and Ajzen's work, the unified theory of acceptance of assistive technology (UTAUT; Venkatesh, Morris, Davis, \& Davis, 2003; Venkatesh, Thong, \& Xu, 2012), centres on the use of technology and may consequently bear a closer relation to AAC use. This model includes: performance expectancy, effort expectancy, social influence, enjoyment, facilitating conditions, and behavioural intent. The first two factors seem to carry the largest weight in shaping behaviour (Davis, Bagozzi, \& Warshaw, 1989; Nam, Bahn, \& Lee, 2013), but the weight of each factor remains contingent upon the behaviour under investigation (Ajzen \& Fishbein, 2005). AAC researchers have not yet applied this model. Considering that a factor's contribution weight may depend on the target behaviour (Ajzen \& Fishbein, 2014), we only include studies here that concern professionals' acceptance of assistive technology.

Liu et al. (2015) in a study on occupational therapists' intention to use technology found that these professionals had a stronger intention to use technology when they believed the technology would be useful and effective (performance expectancy). Their intention was not influenced by the effort it would require (effort expectancy) nor by colleagues' views on technology (social influence; Liu et al., 2015). The therapists' present technology use correlated significantly with facilitating conditions and with their intention to use technology 
in the future. Similar results were found in a study involving special education teachers insofar that performance expectancy, unlike effort expectancy, was positively correlated with intention (Nam et al., 2013). One of the UTAUT's factors, enjoyment, was not included in these studies. Therefore, we also mention a study on the use of computers by pre-service teachers. In that study, behavioural intent increased as enjoyment was higher (Teo, 2012).

Similar to the results from Liu et al. (2015) and Nam et al. (2013), performance expectancy shaped intention, but in Teo's study (2012) this influence was indirect as it was mediated through enjoyment. That is, if the action was perceived as effective and useful, it was more enjoyable, and it was this enjoyment that directly influenced the intention to use computers.

In these studies surveys were utilised which are typically subject to social desirability bias: participants may respond according to prevailing social norms rather than how they feel. By measuring implicit attitude researchers may bypass this bias, and the Implicit Association Test (IAT) is the most widely used implicit test. As opposed to surveys and explicit attitude measurements, implicit tests measure non-deliberated responses by recording reaction times. During an IAT, individuals rapidly categorise words or pictures according to their attributes, and latency times are used to determine implicit attitude. To date, the value of the IAT remains controversial (Ajzen \& Fishbein, 2005; Blanton \& Jaccard, 2006; Payne, Burkley, \& Stokes, 2008) as there is no consensus on the relation between behaviour and implicit attitude. In the field of intellectual disability, there has been a lack of research into this relation. In other fields, implicit attitude has mainly correlated with nonverbal nondeliberated behaviour such as body language (Ajzen \& Fishbein, 2005; Fazio \& Olson, 2003). Whereas Payne et al. (2008) found that implicit attitude measurements had a unique contribution in predicting behaviour over explicit measures, Ajzen and Fishbein (2005) argued that the association 
between implicit attitude measures and behaviour, including nonverbal automated responses, is small.

In attitude studies from various fields, an explicit-implicit attitude discrepancy has been reported (e.g., Hofmann, Gawronski, Gschwendner, Le, \& Schmitt, 2005; Wilson \& Scior, 2014). According to Fazio and Olson (2003), such a discrepancy should not be regarded as reflecting a conscious-unconscious attitude distinction but rather a distinction between implicit and explicit attitude measurements. Researchers demonstrated that the lack of correlation between the IAT and surveys may be bolstered by methodological differences (Hofmann et al., 2005; Payne et al., 2008) including measuring societal versus individual preference (Karpinski \& Steinman, 2006) and disparity in the level of conceptual correspondence with the target behaviour (Ajzen \& Fishbein, 2005; Hofmann et al., 2005).

\subsection{Aim}

Despite concerns in the AAC field about the dependency of AAC use on AAC skills and beliefs, which appears to be shaped by an intricate interrelation of various personal and environmental factors, research addressing these relationships has been lacking. Furthermore, AAC studies have primarily concerned aided strategies, even though research indicated that staff in services for individuals with an intellectual disability may frequently implement KWS and may find this challenging.

Therefore, the relation between KWS attitudes and usage in staff was analysed by conducting implicit and explicit attitude measurements and conversation analysis. In line with the reasoned action approach, we hypothesised that staff with stronger positive KWS attitudes use this AAC strategy more consistently. In addition, the association between perceived control and a discrepancy between intended and actual KWS usage was explored. Furthermore, we examined the relation between professionals' attitude and KWS training.

\section{Methods}


This study has been approved by the Institutional Review Board of the University Hospitals KU Leuven, Belgium (approval number B22201422924). Participants and client representatives had given informed consent, and data were processed anonymously.

\subsection{Participants}

A convenience sample of 12 adults with an intellectual disability participated (clients; see Table A1, for client details). They had all been using KWS for at least a year (Speaking With Support of Signs, Flemish KWS system). Clients were recruited with two communication partners: a familiar speech-language therapist or special educationalist who had completed the official KWS training program (1HT) and a direct support staff member with second-hand KWS training from the client's group home (2HT). Because each communication partner participated with only one client, the 1HT and 2HT group each consisted of 12 professionals. The 1HT professionals had completed an official 6-day training program that teaches all the 500+ signs from Speaking With Support of Signs making them certified to train colleagues. The $2 \mathrm{HT}$ participants had never completed or attended this official training, but had received in-service KWS training from a certified colleague.

The communication partners were asked to indicate the number of signs they could produce and comprehend: (a) 0 to 10 signs, (b) 10 to 50 signs, (c) 50 to 200 signs, or (d) over 200 signs. All 1HT participants reported they could understand as well as produce more than 200 signs. In 2HT, 10 direct support staff reported they could perform between 50 and 200 signs, and two staff members 10 to 50 signs. Ten reported they could understand 50 to 200 signs, and two understood more than 200 signs. For some participants the training had taken place earlier in their career, and other professionals had been trained more recently. On average, 1HT had been using KWS for 17 years $(S D=6$; range $=[7 ; 29])$, and $2 \mathrm{HT}$ for 13 years $(S D=6$; range $=[2 ; 23])$. Also, $1 \mathrm{HT}$ had 23 years of experience in supporting adult clients $(S D=9 ;$ range $=[9 ; 38])$ and 2 HT 18 years $(S D=8 ;$ range $=[3 ; 28])$. 


\subsection{Procedure}

The KWS attitudes of the communication partners were assessed with one explicit attitude measurement, a survey, and one implicit attitude measurement, an IAT. Also, each client was filmed during a dyadic interaction with the $1 \mathrm{HT}$ and the $2 \mathrm{HT}$ familiar staff member. These conversations were set to last at least 10 minutes, after which the researcher turned off the camera when there was a lull in the conversation. The final 10 minutes of each recording were used for analysis. Participants were free to talk about anything, but could also choose from a list of conversation topics that the researcher provided or talk about personal photographs (set-up similar to Lund \& Light, 2007a). The participants were aware that the research pertained to KWS. To reduce biased behaviour in the communication partners, the researcher indicated that the clients' KWS usage was the study's primary focus.

The first author transcribed all 24 recordings (i.e., two videos for 12 clients) and indicated for each utterance which manual signs were produced by the communication partner. To assist in coding, researchers had access to demonstration videos of the 507 manual signs from Speaking With Support of Signs. To assess interrater agreement for the transcription and manual sign coding, one undergraduate student transcribed and coded the videos from three clients and another student the videos from three other clients. Point-bypoint transcription agreement was calculated at word level counting both absent and diverging words as errors. In a first stage, interrater transcription reliability was assessed for two 5minute excerpts. As there was a high level of agreement between the first author and each additional transcriber (i.e., $86 \%$ and 91\%), the researchers continued the transcription without further training. In a second stage, transcription reliability was assessed for $25 \%$ of data using 5-minute excerpts from each of the 12 transcripts processed by the students, which yielded $90 \%$. Coding reliability was assessed for $50 \%$ of the data using the full transcripts processed 
by the students. Point-by-point agreement for the manual sign coding, counting both absent and diverging signs as errors, was $87 \%$.

\subsection{Measures}

A survey was used to gauge each communication partner's explicit attitude towards Speaking With Support of Signs (see Table B1, for survey). The survey items were adopted from Liu et al. (2015), and items that assessed enjoyment were added from Teo (2012). As a result, seven attitude dimensions were incorporated in the survey: performance expectancy, effort expectancy, social influence, use, facilitating conditions, behavioural intent, and enjoyment. The items were adapted making sure they applied to KWS rather than technology (see Table B1, for survey). Also, items from Liu et al. (2015) with explicit reference to a therapy setting were not used as they did not concern direct support staff. Response options were organised as a 7-point labeled Likert scale: (1) strongly disagree, (2) quite disagree, (3) slightly disagree, (4), neither agree nor disagree, (5) slightly agree, (6) quite agree, and (7) strongly agree (Liu et al., 2015). As a pilot, we invited active staff members who used KWS in their interactions with individuals who have an intellectual disability to fill out the survey online. To recruit these staff members, an email was sent to registered special education schools, services for adult clients, and professional associations. After sending these invitations, 234 surveys were completed. To determine which items' scores could be added to form a scaled score, Principal Component Analysis (PCA) was performed on these 234 pilot surveys. This analysis rendered three main explicit attitude scales: Performance Scale, Effort Scale, and Intention Scale.

In addition to this explicit measurement, attitude was also assessed with an implicit measurement, an evaluative single-category IAT (Karpinksi \& Steinman, 2006). The test was administered with the software program Inquisit version 4.0 (2014) using the script from Karpinski and Steinman (2006). The IAT target was Speaking With Support of Signs. In the 
middle of the screen, either pictures appeared of an individual producing a manual sign from this signing system (these pictures constituted a print-screen from the signs' demonstration videos) or universally pleasant or unpleasant words. In preparation of the study, a word list was presented to 120 individuals (based on word lists from IAT studies), and only words that had achieved $100 \%$ agreement on being either pleasant or unpleasant were used in the present IAT (see Table B2). To control for block sequence effects, the test started with the SMOG/unpleasant block across all participants. After a participant took the test, an individual $D$-score was calculated. This score reflects the difference in latency between each block and ranges between -2 and +2 . A negative value indicates that the communication partner had a negative implicit attitude towards KWS and a positive value suggests a positive attitude. Guidelines exist to interpret the strength of these attitudes, but researchers also noted that cutoff scores and zero-lines may be arbitrary (Blanton \& Jaccard, 2006).

Finally, KWS usage was determined by coding the communication partners' KWS usage in the conversation samples. Two sign production measures were used: the number of distinct signs and the proportion of utterances containing at least one key word sign (relative to all utterances). Starting from the reasoned action approach, we investigated the KWS attitudes-usage relation as well as the relation between a potential intention-behaviour discrepancy and the individual's perceived control. We obtained a measure for this discrepancy by converting the proportion of signed utterances and the Intention Scale to $z$ scores and subtracting these scores.

\subsection{Data Analysis}

Statistical tests were performed using the software SPSS Statistics 23 (IBM).

To establish which items' scores may be added to obtain a scaled score, we explored interitem relations by performing PCA on 234 pilot surveys (promax rotation). Prior to this analysis, five variables (items $7,11,12,18,20)$ were excluded because they did not yield 
ample interitem correlations between .30 and .80 (Field, 2009), and one item (item 5) was removed due to a very high interitem correlation $(r=.917)$. During PCA on the remaining 18 items, items that did not load on any factor (i.e., $<.40$ ) were eliminated one by one. This analysis resulted in three explicit attitude scales: Performance Scale, Effort Scale, and Intention Scale. These three scaled scores were calculated for each of the 24 communication partners by adding the items' scores. To allow for an easier comparison between the scores on these scales, each of the added scale scores was divided by the number of items in the respective scale.

These three scaled scores were compared between 1HT and 2HT using Welch $t$ tests (Levene: $.001<p<.141$ ). The between-group difference in implicit attitude scores (i.e., $D$ score from IAT) was analysed with an independent-samples $t$ test. To assess the difference in the proportion of signed utterances between 1HT and 2HT, an ANCOVA was conducted that included KWS experience and number of distinct signs as covariates. Finally, the relation between attitude and sign production was examined with correlational measures. To investigate the relation between KWS intention-usage discrepancy and the individual's perceived control, we correlated the discrepancy score to the Effort scale $z$-score as this scale contained at least three items that related to control perception.

To report effect size, Cohen's $d$ was used and in the case of non-parametric testing the Pearson correlation measure $r$ (Fritz, Morris, \& Richler, 2012). Significance of $p$-values was assessed at a level of $\alpha=.05$.

\section{Results}

\subsection{Attitude towards Key Word Signing}

To assess the interitem relations between the survey's items, we performed PCA with promax rotation on the 234 pilot surveys $($ Determinant $=.001 ;$ Kaiser-Meyer Olkin $=.879$; Bartlett's Test of Sphericity: $\left.\mathrm{X}^{2}(78)=1676.18 ; p=.001\right)$. This resulted in three explicit 
attitude scales that can be described as Performance Scale (Cronbach $\alpha=.868$ ), Effort Scale (Cronbach $\alpha=.808)$, and Intention Scale (Cronbach $\alpha=.800)$. These scales each accounted for respectively $47 \%, 12 \%$, and $8 \%$ of total variance (see Table 1 ; Table B1).

A Welch $t$ test on the scaled scores from the 24 communication partners showed that the difference between 1HT and 2HT reached significance on the Performance Scale $\left(t_{w}(18.51)=6.80 ; p=.018 ; d=1.06\right)$ and the Effort Scale $\left(t_{w}(13.57)=11.32 ; p=.005 ; d=\right.$ $1.37)$, but not on the Intention Scale $\left(t_{w}(15.16)=4.73 ; p=.053 ; d=0.85\right)$. Despite statistical significance, scores were only slightly higher in 1HT compared to 2HT (Performance Scale: 1HT $X=6.73 ; 2 \mathrm{HT} X=6.22$. Effort Scale: $1 \mathrm{HT} X=6.58 ; 2 \mathrm{HT} X=5.80)$. Also, a ceiling effect was discerned in 1HT's explicit attitude scores: 92\% of 1HT scored higher than 6 on the Effort Scale as opposed to $42 \%$ of $2 \mathrm{HT}$. This difference in distribution was smaller for the Performance Scale, with $83 \%$ of $1 \mathrm{HT}$ and $58 \%$ of $2 \mathrm{HT}$ scoring higher than 6 . All participants from $1 \mathrm{HT}$ and $2 \mathrm{HT}$ scored higher than 4 on all three scales, indicating that each participant held positive explicit attitudes.

$<$ Please insert Table 1 about here $>$

On the implicit attitude measurement ( $D$-score on IAT) too, 1HT and 2HT scored significantly different $(t(22)=2.13 ; p=.045 ; d=.87)$. On average, 1 HT achieved stronger positive implicit attitude scores $(M=.39 ; S D=.36)$ than $2 \mathrm{HT}(M=.08 ; S D=.34)$. Similar results were found using categorised rather than continuous implicit scores $(U=37.50 ; p=$ $.045 ; r=-.413 ; M d n 1 \mathrm{HT}$ vs. $2 \mathrm{HT}=$ mild to moderate positive vs. no/little positive): $75 \%$ of $1 \mathrm{HT}$ had a mild to strong positive implicit attitude, as opposed to $50 \%$ in $2 \mathrm{HT}$. The implicit attitude measurement did not correlate significantly with the Performance Scale $\left(r_{s}=.319 ; p=\right.$ $.129)$, the Effort Scale $\left(r_{s}=.232 ; p=.274\right)$, or the Intention Scale $\left(r_{s}=.051 ; p=.813\right)$.

\subsection{Key Word Signing Usage}

The number of distinct signs and proportion of signed utterances was higher in 1HT than 2HT (see Table 2). An ANCOVA $\left(R^{2}=.567\right)$ was performed with the proportion of 
signed utterances. This model included training background as independent variable and the number of distinct signs and KWS experience as covariates. Results showed that the effect of training background was mediated by the number of distinct signs. That is, training did not have a significant effect $(F(1)=.769 ; p=.391 ; d=.40)$ on the proportion of signed utterances in a model that controlled for the number of distinct signs $(F(1)=13.53 ; p=.001 ; d=1.65)$ and KWS experience $(F(1)=.14 ; p=.710 ; d=.17)$.

$<$ Please insert Table 2 about here $>$

\subsection{Relation between Attitude and Sign Usage}

The implicit attitude measurement had a positive linear relation to the proportion of signed utterances $\left(r=.437 ; p=.033 ; R^{2}=.452\right.$; see Figure 1$)$. Concerning the explicit attitude measurements, no significant correlation was found between the proportion of signed utterances and the Performance Scale $\left(r_{s}=.375 ; p=.071\right)$, the Effort Scale $\left(r_{s}=.135 ; p=\right.$ $.529)$, or the Intention Scale $\left(r_{s}=.055 ; p=.797\right)$. In contrast, the discrepancy score significantly correlated with the Effort Scale score $(r=-.529, p=.008$; see Figure 2$)$. Visual examination of the data showed that this linear relation was present in $2 \mathrm{HT}\left(R^{2}=.637\right)$, but not 1HT $\left(R^{2}=.013\right)$. 


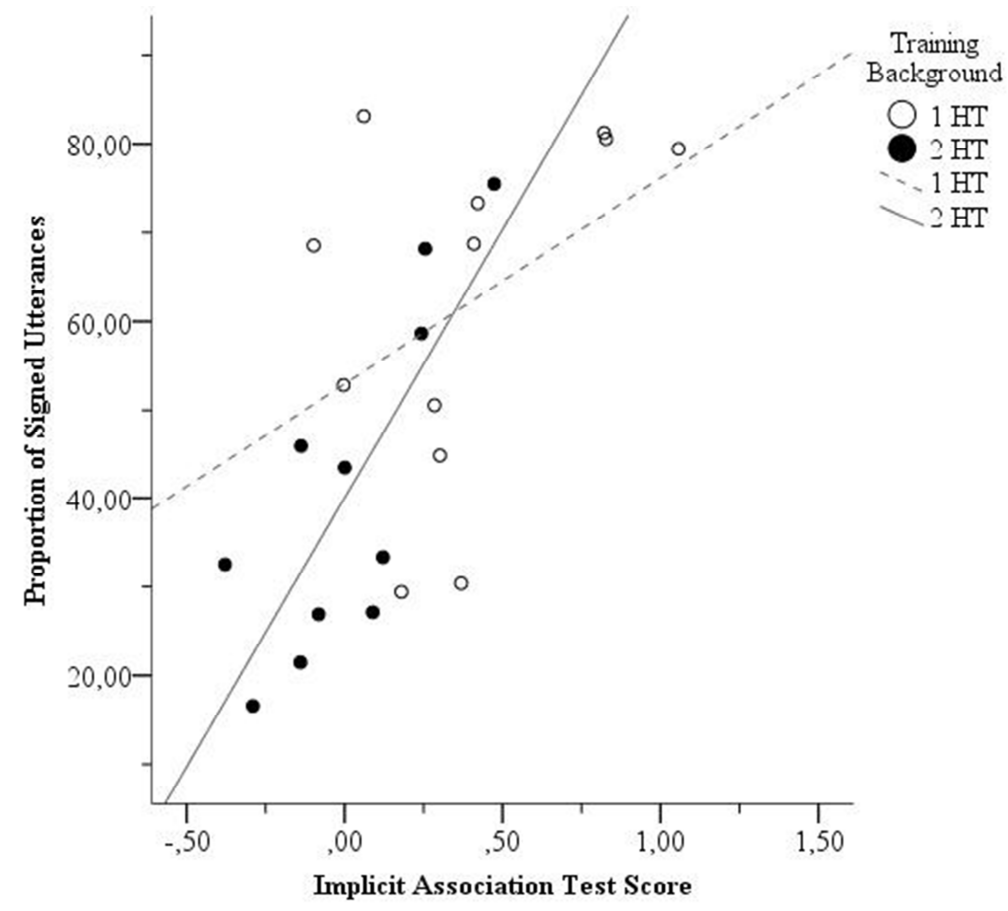

Figure 1. Key word signing usage and implicit attitude. Scatterplot showing a positive linear relation between the proportion of key word signing utterances (percentage) and the Implicit Association Test scores ( $D$-score) concerning support staff. 1HT = professionals with firsthand key word signing training; $2 \mathrm{HT}=$ direct support staff with second-hand key word signing training.

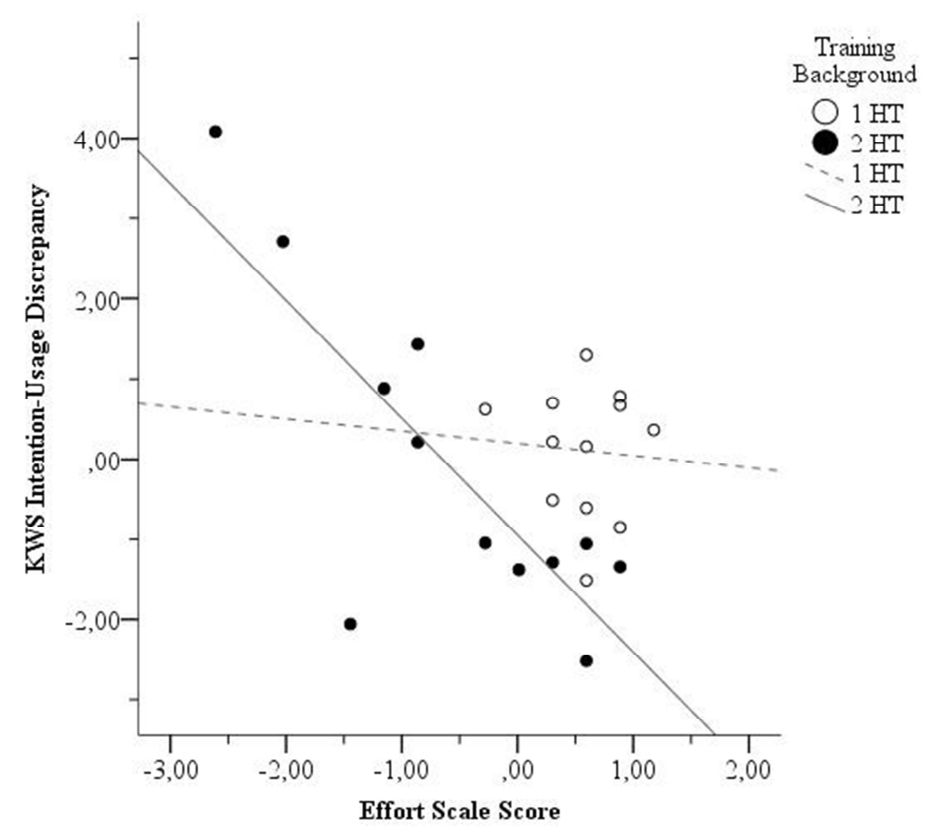

Figure 2. The intention-behaviour discrepancy related to perceived control. Scatterplot showing for 2HT a negative linear relation between the intention-usage discrepancy ( $z$-score) and the Effort Scale ( $z$-score). 1HT = professionals with first-hand key word signing training; $2 \mathrm{HT}=$ direct support staff with second-hand key word signing training. 


\section{Discussion}

In this study, the relation between professionals' KWS attitudes and usage was examined in professionals with first-hand KWS training and direct support staff with secondhand KWS training. Results indicated that 1HT produced more KWS because they knew more distinct signs than 2 HT. Also, there was a positive relation between implicit attitude (IAT) and KWS usage in staff but no association between explicit attitude (survey) and KWS application.

PCA on 234 pilot surveys resulted in three explicit attitude scales: Performance Scale, Effort Scale, and Intention Scale. The 1HT group scored significantly higher on the first two explicit attitude scales. Despite this statistical significance, the clinical difference was insignificant as both 1HT and 2HT achieved positive scores on the Performance Scale and the Effort Scale. In line with the interview study of Trembath et al. (2014), the views of direct support staff on KWS varied, particularly concerning the efforts and enjoyment in using KWS.

The implicit attitude measurement ( $D$-score on IAT) yielded a larger difference. Despite the fact that 1HT had a stronger positive implicit attitude than 2HT, causal relations between attitude and type of training cannot be drawn from the present findings. Apart from the type of training, a number of additional factors may have played a role: (a) 1HT had voluntarily completed an official KWS training program once and consequently may have been more motivated, (b) 1HT's educational background and working circumstances were different from $2 \mathrm{HT}$.

The absent correlation between the implicit and explicit attitude measures concurs with attitude studies from various fields (for review, Ajzen \& Fishbein, 2005; Fazio \& Olson, 2003; Hofmann et al., 2005; Wilson \& Scior, 2014). It has been argued that a small implicitexplicit attitude correlation can be associated with differences in measurement parameters 
between an IAT and a survey (Ajzen \& Fishbein, 2005; Payne et al., 2008). Therefore, it would be interesting to ascertain whether changing IAT parameters so they approximate the survey structure increases the implicit-explicit attitude correlation.

The professionals' KWS usage also diverged: $62 \%$ of all utterances was produced with KWS in $1 \mathrm{HT}$ as opposed to $37 \%$ in $2 \mathrm{HT}$. These results are in line with previous findings that less training may impede AAC implementation (Calculator, 1999; Johnson et al., 2006; Lund \& Light, 2007b). Nevertheless, the proportion of signed utterances was contingent upon training background only insofar that training determined the number of distinct signs that the professionals knew and used. Researchers proposed to organise staff training in a train-thetrainer or pyramidal system (e.g., Bloomberg, West, \& Iacono, 2003; Meuris, Maes, \& Zink, 2015), but the present results indicate that in-service KWS training does not yet reach its full potential as it may not be sufficiently comprehensive. As a consequence, a client may be supported by professionals who diverge in KWS usage. To understand how clients' KWS use may be influenced by communication partners' inconsistent KWS use, further research is needed.

Video-recording the conversations may have induced participant reactivity: individuals perhaps behaved differently because they were being observed. Exposing participants to a video camera for a shorter period of time may mitigate this influence (Gross, 1991; Haidet, Tate, Divirgilio-thomas, Kolanowski, \& Happ, 2009). In the present study, we observed that some communication partners used KWS fluently, whereas others expressed doubt during the performance of a manual sign. This observation gave rise to the question to what extent the participants used KWS in everyday situations. Researchers aiming to fully capture the intricate influence from co-occurring environmental factors should consider conducting naturalistic observations without a video camera. 
Social psychologists and AAC researchers have argued that attitudes shape behaviour. Professionals with a positive implicit attitude were more inclined to use KWS. In contrast, the three explicit attitude scales (i.e., Performance, Effort, and Intention Scale) were not related to KWS usage, which suggests that surveys may fail to measure the complex interrelation of factors surrounding AAC use. Consequently, in clinical settings surveys may lack sensitivity to adequately predict or evaluate AAC implementation. Nevertheless, the discrepancy between the professionals' actual KWS usage and their score on the Intention Scale correlated significantly with the Effort Scale. This finding supports the reasoned action approach (Fishbein \& Ajzen, 2010): as perceived control rose, the discrepancy between intended and actual KWS usage declined. In future studies, AAC researchers may focus on the effects that regular group interviews with support staff may have on their KWS usage. Such interviews may possibly be beneficial to the control perception of staff (control beliefs; Fishbein \& Ajzen, 2010) and team collaboration. Further, staff might be more inclined to use KWS or other AAC strategies when they can exchange experiences, particularly if interviews are accompanied by hands-on demonstrations of AAC usage (Bradshaw \& Goldbart, 2013; Graves, 2007).

It should be noted that interpretation of the present results was complicated by the small sample size and by the complexity of various factors interacting upon KWS usage. Replicating this research with a larger sample of participants is warranted. Regression analyses (e.g., Keith, Bennetto, \& Rogge, 2015) and structural equation modeling (e.g., Nam et al., 2013; Teo, 2012) are suitable methods for examining the presence and weight of factorial relations and their association with behaviour. These analyses could not be conducted in the present study as they typically require large sample sizes. This would have meant including at least 90 participants (Field, 2009), which was not feasible due to the timeconsuming conversation analysis. Consequently, we cannot draw strong conclusions. Despite 
the reduced generalizability of its results, qualitative research may provide valuable insights (Balandin \& Goldbart, 2011). Though the present findings may not be generalized to all professionals who use KWS, they enhance understanding of KWS implementation.

\section{Conclusions}

Both quantitative (e.g., Chadwick \& Jolliffe, 2008; Meuris, et al. 2015) and qualitative research (e.g., Torrison, Jung, Baker, Beliveau, \& Cook, 2007; Trembath et al., 2014) indicated that staff may use AAC inconsistently. Communication partners' attitudes may be an important determinant of AAC usage, as evidenced by various AAC training programs for communication partners that incorporated psychoeducation. According to clients and staff, the consistency of AAC use is influenced by the stakeholders' attitudes towards AAC (Calculator, 1999; Johnson, Inglebret, Jones, \& Ray, 2006; Lund \& Light, 2007b).

In this study, professionals' KWS use was observed during staff-client interactions, and related to these professionals' implicit (IAT) and explicit attitude (survey) scores. Results showed a positive linear relation between implicit attitude and KWS usage. In comparison with 2HT, 1HT had stronger positive IAT scores and produced more distinct signs as well as more signed utterances. The 2HT group produced less KWS than 1HT because they knew fewer manual signs. No association was found between explicit attitude scores and KWS use, which suggests that the survey did not capture the complex influences that shape AAC use despite that it included seven attitude domains that are grounded in widely accepted social psychology models (Fishbein \& Ajzen, 2010; Venkatesh et al., 2012).

From the results, we may cautiously argue that all communication partners believed in KWS effectiveness and intended to use KWS, but that effortful KWS usage and training could hinder their actual usage. Staff with more extensive KWS training were more proficient in KWS and applied it more consistently. These findings suggests that consistent KWS usage in direct support staff may be facilitated by more extensive KWS training if this enhanced 
Accepted for publication in Research in Developmental Disabilities

training does not increase (perceived) effort. Therapists evaluating KWS implementation and training programs in their service may gain more profound insights by conducting interviews that specifically focus on the (perceived) efforts that accompany KWS usage and training. 
Accepted for publication in Research in Developmental Disabilities

\section{Acknowledgements}

This study is part of the first author's $\mathrm{PhD}$ project that concerns AAC usage in direct support staff. We are very grateful to the clients, direct support staff, speech-language therapists, and special educationalists for participating. We would also like to thank the students for assisting in the transcription and coding of the videos. The authors are also grateful to the Foundation Marguerite-Marie Delacroix for financially supporting this project. There was no conflict of interest and no restrictions were imposed on the publication of results or on access to data. 
Accepted for publication in Research in Developmental Disabilities

\section{References}

Ajzen, I., \& Fishbein, M. (2005). The influence of attitudes on behavior. In D. Albarracín, B. T. Johnson, \& M. P. Zanna (Eds.), The handbook of attitudes (pp. 173-221). New York: Psychology Press.

Balandin, S., \& Goldbart, J. (2011). Qualitative research and AAC: Strong methods and new topics. Augmentative and Alternative Communication, 27, 227-228.

Beck, A. R., Stoner, J. B., \& Dennis, M. L. (2009). An investigation of aided language stimulation: Does it increase AAC use with adults with developmental disabilities and complex communication needs? Augmentative and Alternative Communication, 25, 42-54. doi:10.1080/07434610802131059

Beukelman, D. R., \& Mirenda, P. (2013). Augmentative and Alternative Communication: Supporting children and adults with complex communication needs. Baltimore: Brookes.

Blanton, H., \& Jaccard, J. (2006). Arbitrary metrics in psychology. The American Psychologist, 61, 27-41. doi:10.1037/0003-066X.61.1.62

Bloomberg, K., West, D., \& Iacono, T.A. (2003). PICTURE IT: An evaluation of a training program for carers of adults with severe and multiple disabilities. Journal of Intellectual and Developmental Disability, 28, 260-282. doi:10.1080/1366825031000150964

Bradshaw, J., \& Goldbart, J. (2013). Staff views of the importance of relationships for knowledge development: Is training by specialists a waste of money? Journal of Applied Research in Intellectual Disabilities, 26, 284-298. doi:10.1111/jar.12020

Calculator, S. (1999). AAC outcomes for children and youths with severe disabilities: When seeing is believing. Augmentative and Alternative Communication, 15, 4-12. doi:10.1080/07434619912331278525 
Accepted for publication in Research in Developmental Disabilities

Chadwick, D. D., \& Jolliffe, J. (2009). A pilot investigation into the efficacy of a signing training strategy for staff working with adults with intellectual disabilities. British Journal of Learning Disabilities, 37, 34-42. doi:10.1111/j.1468-3156.2008.00503.x

Cohen, J. (1988). Statistical power analysis for the behavioral sciences. Hillsdale: Erlbaum.

Davis, F. D., Bagozzi, R. P., \& Warshaw, P. R. (1989). User acceptance of computer technology: A comparison of two theoretical models. Management Science, 35, 9821003. doi:10.1287/mnsc.35.8.982

Dodd, J. L., \& Gorey, M. (2014). AAC Intervention as an Immersion Model. Communication Disorders Quarterly, 35, 103-107. doi:10.1177/1525740113504242

Dunn, L., M., \& Dunn, L. M. (2005). Peabody Picture Vocabulary Test-III-NL (L. Schlichting, Dutch version). Amsterdam, the Netherlands: Pearson.

Fazio, R. H., \& Olson, M. a. (2003). Implicit measures in social cognition research: Their meaning and use. Annual Review of Psychology, 54, 297-327. doi:10.1146/annurev.psych.54.101601.145225

Field, A. (2009). Discovering statistics using SPSS: (and sex and drugs and rock 'n roll). Los Angeles: Sage.

Fishbein, M., \& Ajzen, I. (1975). Belief, attitude, intention and behavior: An introduction to theory and research. Reading, MA: Addison-Wesley.

Fishbein, M., \& Ajzen, I. (2010). Predicting and changing behavior: The reasoned action approach. New York: Psychology press.

Graves, J. (2007). Factors influencing indirect speech and language therapy interventions for adults with learning disabilities: The perceptions of carers and therapists. International Journal of Language and Communication Disorders, 42(S1), 103-121. doi:10.1080/13682820601171373 
Hamm, B., \& Mirenda, P. (2006). Post-school quality of life for individuals with developmental disabilities who use AAC. Augmentative and Alternative Communication, 22, 134-147. doi:10.1080/07434610500395493

Hofmann, W., Gawronski, B., Gschwendner, T., Le, H., \& Schmitt, M. (2005). A metaanalysis on the correlation between the implicit association test and explicit self-report measures. Personality and Social Psychology Bulletin, 31, 1369-1385. doi:1177/0146167205275613

Inquisit 4.0.8.0 [Computer software]. (2014). Seattle, WA: Millisecond Software.

Johnson, J. M., Inglebret, E., Jones, C., \& Ray, J. (2006). Perspectives of speech language pathologists regarding success versus abandonment of AAC. Augmentative and Alternative Communication, 22, 85-99. doi:10.1080/07434610500483588

Karpinski, A., \& Steinman, R. B. (2006). The single category implicit association test as a measure of implicit social cognition. Journal of Personality and Social Psychology, 91, 16-32. doi:10.1037/0022-3514.91.1.16

Keith, J. M., Bennetto, L., \& Rogge, R. D. (2015). The relationship between contact and attitudes: Reducing prejudices towards individuals with intellectual and developmental disabilities. Research in Developmental Disabilities, 47, 14-26.

Liu, L., Miguel Cruz, A., Rios Rincon, A., Buttar, V., Ranson, Q., \& Goertzen, D. (2015). What factors determine therapists' acceptance of new technologies for rehabilitation A study using the Unified Theory of Acceptance and Use of Technology (UTAUT). Disability and Rehabilitation, 37(5), 1-9. doi:10.3109/09638288.2014.923529

Lund, S. K., \& Light, J. (2007a). Long-term outcomes for individuals who use Augmentative and Alternative Communication: Part II--communicative interaction. Augmentative and Alternative Communication, 23, 1-15. doi:10.1080/07434610600720442 
Accepted for publication in Research in Developmental Disabilities

Lund, S. K., \& Light, J. (2007b). Long-term outcomes for individuals who use Augmentative and Alternative Communication: Part III--contributing factors. Augmentative and Alternative Communication, 23, 323-335. doi:10.1080/02656730701189123

McCall, F., Markova, I., Murphy, J., Moodie, E., \& Collins, S. (1997). Perspectives on AAC systems by the users and by their communication partners. European Journal of Disorders of Communication, 32, 235-256. doi: 10.1080/13682829709177099

Meuris, K., Maes, B., \& Zink, I. (2014). Key word signing usage in residential and day care programs for adults with intellectual disability. Journal of Policy and Practice in Intellectual Disabilities, 11, 255-267. doi:10.1111/jppi.12093

Meuris, K., Maes, B., \& Zink, I. (2015). Teaching adults with intellectual disability manual signs through their support staff: A key word signing program. American Journal of Speech-Language Pathology, 24, 545-560. doi:10.1044/2015_AJSLP-14-0062

Murphy, J., Markova, I., Collins, S., \& Moodie, E. (1996). AAC systems: Obstacles to effective use. European Journal of Disorders of Communication, 31, 31-44. doi: $10.3109 / 13682829609033150$

Nam, C. S., Bahn, S., \& Lee, R. (2013). Acceptance of assistive technology by special education teachers: A structural equation model approach. International Journal of Human-Computer Interaction, 29, 365-377. doi:10.1080/10447318.2012.711990

Payne, B. K., Burkley, M. a, \& Stokes, M. B. (2008). Why do implicit and explicit attitude tests diverge? The role of structural fit. Journal of Personality and Social Psychology, 94, 16-31. doi:10.1037/0022-3514.94.1.16

Purcell, M., McConkey, R., \& Morris, I. (2000). Staff communication with people with intellectual disabilities: The impact of a work based training programme. International Journal of Language \& Communication Disorders, 35, 147-158.

doi:10.1080/136828200247313 
Rombouts, E., Maes, B., \& Zink, I. (2015). The behavioural process underlying augmentative and alternative communication usage in direct support staff. Journal of Intellectual and Developmental Disability.

Schlosser, R. (1999). Social validation of interventions in Augmentative and Alternative Communication. Augmentative and Alternative Communication, 15, 234-147. doi:10.1080/07434619912331278775

Smith, M. M., \& Connolly, I. (2008). Roles of aided communication: Perspectives of adults who use AAC. Disability and Rehabilitation: Assistive Technology, 3, 260-273. doi:10.1080/17483100802338499

Stans, S. E. A., Dalemans, R., de Witte, L., \& Beurskens, A. (2013). Challenges in the communication between "communication vulnerable" people and their social environment: An exploratory qualitative study. Patient Education and Counseling, 92, 302-312. doi:10.1016/j.pec.2013.05.021

Teo, T. (2012). Examining the intention to use technology among pre-service teachers: An integration of the Technology Acceptance Model and Theory of Planned Behavior. Interactive Learning Environments, 20, 3-18. doi:10.1080/10494821003714632

Torrison, C., Jung, E., Baker, K., Beliveau, C., \& Cook, A. (2007). The impact of staff training in Augmentative/Alternative Communication (AAC) on the communication abilities of adults with developmental disabilities. Developmental Disabilities Bulletin, $35,103-130$.

Trembath, D., Iacono, T., Lyon, K., West, D., \& Johnson, H. (2014). Augmentative and alternative communication supports for adults with autism spectrum disorders. Autism, 18, 891-902. doi:10.1177/1362361313486204 
Accepted for publication in Research in Developmental Disabilities

Venkatesh, V., Morris, M. G., Davis, G. B., \& Davis, F. D. (2003). User acceptance of information technology: Toward a unified view. MIS Quarterly, 27, 425-478. doi: 10.1006/imms. 1993.1022

Venkatesh, V., Thong, J. Y. L., \& Xu, X. (2012). Consumer acceptance and use of information technology: Extending the unified theory of acceptance and use of technology. MIS Quarterly, 36, 1-22.

Wilson, M. C., \& Scior, K. (2014). Attitudes towards individuals with disabilities as measured by the Implicit Association Test: A literature review. Research in Developmental Disabilities, 35, 294-321. doi:10.1016/j.ridd.2013.11.003 
Accepted for publication in Research in Developmental Disabilities

Table 1

Loadings from Principal Component Analysis on Survey

\begin{tabular}{|c|c|c|c|c|}
\hline Item & Attitude domain & Component 1 & Component 2 & Component 3 \\
\hline 1 & Performance expectancy & .005 & .762 & .042 \\
\hline 2 & Performance expectancy & -.079 & .820 & -.080 \\
\hline 3 & Performance expectancy & .132 & .622 & .170 \\
\hline 4 & Intention & -.088 & -.068 & .993 \\
\hline 5 & Intention & -.033 & .109 & .854 \\
\hline 8 & Use & .140 & .707 & -.166 \\
\hline 13 & Facilitating conditions & -.148 & .823 & .091 \\
\hline 16 & Facilitating conditions & .147 & -.072 & .817 \\
\hline 17 & Facilitating conditions & .904 & -.092 & .033 \\
\hline 19 & Effort expectancy & .875 & -.013 & -.095 \\
\hline 21 & Effort expectancy & .937 & -.109 & .034 \\
\hline 23 & Attitude towards use (enjoyment) & .608 & .202 & .010 \\
\hline 24 & Attitude towards use (enjoyment) & .492 & .322 & .071 \\
\hline
\end{tabular}

Note. Factor loadings $>.4$ are in boldface (Field, 2009). Item number equals item number from Table B1. Items from Liu et al. (2015) and Teo (2012) were adopted, and the domains refer to their work. 
Accepted for publication in Research in Developmental Disabilities

Table 2

Difference in Sign Usage between the Communication Partners with First- and Second-Hand Key Word Signing Training

\begin{tabular}{|c|c|c|c|c|c|c|c|c|c|}
\hline \multirow[b]{2}{*}{ Sign production } & \multicolumn{3}{|c|}{ Mean } & \multirow[b]{2}{*}{$\begin{array}{c}\text { Standard } \\
\text { error }^{\mathrm{a}}\end{array}$} & \multirow[b]{2}{*}{$95 \% \mathrm{CI}^{\mathrm{a}}$} & \multirow[b]{2}{*}{$t$ statistic } & \multirow[b]{2}{*}{$d f$} & \multirow[b]{2}{*}{$p$-value } & \multirow[b]{2}{*}{$\begin{array}{l}\text { Effect size } \\
\qquad(d)^{\mathrm{b}}\end{array}$} \\
\hline & $1 \mathrm{HT}$ & $2 \mathrm{HT}$ & Difference & & & & & & \\
\hline $\begin{array}{l}\text { Total number } \\
\text { of signs }\end{array}$ & 127 & 68 & 59 & 21.37 & {$[20.46 ; 97.55]$} & 3.17 & 22 & .004 & 1.30 \\
\hline $\begin{array}{l}\text { Number of } \\
\text { distinct signs }\end{array}$ & 61 & 39 & 22 & 9.03 & {$[6.23 ; 37.27]$} & 2.91 & 22 & .008 & 1.19 \\
\hline $\begin{array}{l}\text { Proportion of } \\
\text { signed utterances (\%) }\end{array}$ & 62 & 37 & 25 & 10.41 & {$[6.70 ; 41.30]$} & 2.88 & 22 & .009 & 1.17 \\
\hline
\end{tabular}

Note. $1 \mathrm{HT}=$ professionals with first-hand key word signing training; $2 \mathrm{HT}=$ direct support staff with second-hand key word signing training; $\mathrm{CI}$

$=$ confidence interval; $\mathrm{df}=$ degrees of freedom.

${ }^{\mathrm{a}}$ For difference; ${ }^{\mathrm{b}}$ small effect when Cohen's $d=.2$, medium effect when $d=.5$, large effect when $d=.8$ (Cohen, 1988) 
Accepted for publication in Research in Developmental Disabilities

Appendix A

Table A1

Individual Profiles of the Adults with an Intellectual Disability

\begin{tabular}{ccllcccl}
\hline Client & Age & Etiology & Degree of ID & PPVT $^{\mathrm{a}}$ & MLU-V $^{\mathrm{c}}$ & MLU-S $^{\mathrm{c}}$ & Primary reason for KWS usage \\
\hline 1 & 46 & Down syndrome & severe & 47 & 1.0 & 1.0 & Speech difficulties \\
2 & 36 & Down syndrome & severe & 54 & 2.0 & 2.5 & Speech difficulties \\
3 & 31 & Premature birth & severe & 63 & 2.6 & 2.3 & Speech difficulties, language production \\
4 & 37 & Down syndrome & severe & 44 & 2.0 & 1.8 & Speech difficulties, language \\
& & & & & & production, language comprehension \\
5 & 54 & Down syndrome & severe & 25 & 1.0 & 1.2 & Speech difficulties \\
7 & 34 & Klinefelter syndrome & severe & 72 & 1.3 & 1.3 & Speech difficulties \\
8 & 24 & Onknown & moderate & 71 & 2.0 & 1.5 & Speech difficulties \\
9 & 30 & Down syndrome & moderate & 93 & 3.9 & 6.0 & Speech difficulties \\
10 & 26 & Unknown & severe & 69 & 3.2 & 3.4 & Speech difficulties, language production
\end{tabular}


Accepted for publication in Research in Developmental Disabilities

$\begin{array}{llllllll}11 & 49 & \text { Down syndrome } & \text { moderate } & 71 & 2.0 & 2.5 & \text { Speech difficulties } \\ 12 & 26 & \text { Premature birth } & \text { moderate } & 63 & 2.4 & 2.3 & \text { Speech difficulties }\end{array}$

Note. MLU-V = Mean Length Utterance for utterances not containing key word signing; MLU-S = Mean Length Utterance for utterances containing at least one key word sign.

${ }^{a}$ Based on report from in-service communication specialist as recent IQ-scores were not always available; ${ }^{b}$ raw scores from Peabody Picture

Vocabulary Test-III-NL (Dunn \& Dunn, 2005); ${ }^{c}$ MLU was calculated for both conversation samples, and the highest MLU has been reported. 
Accepted for publication in Research in Developmental Disabilities

Appendix B

Table B1

Survey items and Associated Attitude Components

\begin{tabular}{llll}
\hline Item & & Original Component & Present Component \\
\hline 1 & Using key word signing improves clients' day-to-day communication. & Performance expectancy & Performance Scale \\
3 & Using key word signing can improve the quality of my work. & Performance expectancy & Performance Scale \\
4 & Using key word signing makes it easier for me to support my clients. & Performance expectancy & Performance Scale \\
5 & I will continue to use key word signing in the future. & Intention & Intention Scale \\
6 & I plan to use key word signing more often in the next months. & Intention & Intention Scale \\
7 & I use key word signing because it supports clients' self-determination. & Use & Performance Scale \\
8 & I use key word signing to improve clients' socioemotional wellbeing. & Use & \\
9 & I use key word signing to improve clients' language production and & Use &
\end{tabular}


signing or are enthusiastic about learning it.

11 Generally speaking, the service supports the use of key word signing.

12 Staff who use key word signing have more prestige.

13 Key word signing suits my client's needs.

14 If I need assistance regarding key word signing, I can count on certain professionals.

15 I have sufficient means to use key word signing.

16 I have opportunity to use key word signing.

17 I have sufficient sign knowledge to use key word signing.

18 Learning new manual signs would be easy for me.

19 I find key word signing easy to use.

20 It does not take up a lot of time to maintain key word signing

21 With key word signing I can say what I want.

22 Key word signing makes my work interesting.

23 Key word signing is fun.
Social influence

Social influence

Facilitating conditions

Performance Scale

Facilitating conditions

Facilitating conditions

Facilitating conditions

Intention Scale

Facilitating conditions

Effort Scale

Effort expectancy

Effort Scale

Effort expectancy

Effort expectancy

Effort expectancy

Effort Scale

Attitude towards use

Attitude towards use
Effort Scale 
Accepted for publication in Research in Developmental Disabilities

$24 \quad$ I like using key word signing.

Attitude towards use

Effort Scale

Note. Items from Liu et al. (2015) and Teo (2012) were adapted, and the original components refer to their work. Items without a present component are items that were excluded in the present study prior to or during Principal Component Analysis. 
Accepted for publication in Research in Developmental Disabilities

Table B2

List of Attribute Words from the Key Word Signing Single-Category Implicit Association Test

\begin{tabular}{ll}
\hline Pleasant & Unpleasant \\
\hline Beautiful & Hate \\
Friendly & Disgust \\
Happy & Nightmare \\
Fun & Tragic \\
Nice & Disaster \\
Peace & Fail \\
Admire & Poison \\
Success & Painful \\
Cozy & Sad \\
Cheerful & Shame \\
Paradise & Humiliate \\
\hline
\end{tabular}

